\title{
Expression of estrogen receptor $\alpha$ and $\beta$ in esophageal squamous cell carcinoma
}

\author{
JING DONG $^{1 *}$, SHI-WEN JIANG ${ }^{1,5^{*}}$, YANRU NIU ${ }^{1}$, LING CHEN $^{2}$, SHUYAN LIU $^{1}$, TIANZHONG MA ${ }^{1}$,

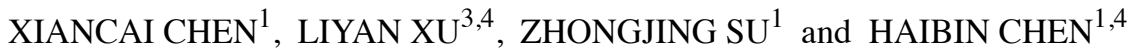 \\ Departments of ${ }^{1}$ Histology and Embryology, ${ }^{2}$ Biochemistry and Molecular Biology, and \\ ${ }^{3}$ Institute of Oncologic Pathology, Shantou University Medical College, Shantou, Guangdong; \\ ${ }^{4}$ Key Laboratory of Oncomolecular Biology in Chaoshan Littoral Area, Guangdong, P.R. China; \\ ${ }^{5}$ Department of Biomedical Science, Mercer University School of Medicine, Savannah, GA, USA
}

Received August 16, 2013; Accepted September 17, 2013

DOI: 10.3892/or.2013.2770

\begin{abstract}
Estrogen receptors (ERs) are frequently expressed in human tumor tissues. There have been several studies concerning ER expression in esophageal cancers, yet the results are inconsistent, and the prognostic value of the receptors remains unclear. In the present study, we investigated the expression of ER protein and its correlation with clinical features of esophageal squamous cell carcinoma (ESCC) patients.Immunohistochemical staining for the ERs was carried out on paraffin-embedded primary tumor tissue sections from 89 patients with ESCC. Quantitative analyses were performed to determine the prognostic value of the expression of ERs, and Pearson's correlation was used to examine the relationship between ER $\alpha$ and ER $\beta$ expression levels. Our results showed that $\mathrm{ER} \alpha$ immunoreactivity was significantly lower in ESCC than that in the non-neoplastic epithelium $(\mathrm{P}=0.0445)$, whereas the ER $\beta$ status was much stronger in ESCC than that in the non-neoplastic epithelium $(\mathrm{P}=0.0243)$. A significant inverse correlation was observed between ER $\alpha$ expression and depth of tumor invasion $(\mathrm{P}=0.0426)$. Correlation analysis revealed a statistically significant inverse correlation between the expression of $\mathrm{ER} \alpha$ and $\mathrm{ER} \beta$ in ESCC ( $\mathrm{r}=-0.2902, \mathrm{P}=0.0058)$. Kaplan-Meier survival analysis showed that the patients with ER $\alpha$ expression (21/89) had a better outcome than patients without ER $\alpha$ expression $(\mathrm{P}=0.0280)$, whereas patients with high ER $\beta$ immunoreactivity (44/89) were significantly associated with worse survival $(\mathrm{P}=0.0366)$. In conclusion, $\mathrm{ER} \alpha$ and $\mathrm{ER} \beta$ levels were inversely correlated, and the downregulation
\end{abstract}

Correspondence to: Professor Haibin Chen, Department of Histology and Embryology, Shantou University Medical College, 22 Xinling Road, Shantou, Guangdong 515041, P.R. China

E-mail: chenhb@stu.edu.cn

*Contributed equally

Key words: esophageal carcinoma, estrogen receptor, immunohistochemistry, histopathology of $\operatorname{ER} \alpha$ and upregulation of ER $\beta$ may indicate unfavorable prognosis of ESCC.

\section{Introduction}

Human esophageal squamous cell carcinoma (ESCC) is one of the most aggressive malignancies. Prominent gender differences in the prevalence of ESCC have been demonstrated by most epidemiological studies. Esophageal cancer is generally more common among males than females, with a male to female ratio exceeding 3-4:1 (1). The prognosis of ESCC female patients is significantly better than that of male patients (2). While these data indicate the potential involvement of sex hormone-related pathways in the pathogenesis of ESCC, the relevant molecular events remain unclear.

Previous studies suggest a possible correlation between the estrogenic pathway and tumorigenesis and/or progression of ESCC $(3,4)$. Esophageal cancer in females tends to occur postmenopausally, and the incidence rate for females increases with age (5). Sex steroids, such as estrogen, are well-known for their role(s) in the control of cell differentiation and proliferation in estrogen-dependent tissues such as breast and endometrial tissues. However, it is noteworthy that estrogens appear to play a pivotal role in several types of human malignancies that are not considered as classical, estrogen-dependent, neoplasms, such as lung (6,7), urinary bladder (8) and gastrointestinal tract malignancies $(9,10)$. Consequently, estrogenic pathways may be involved in the regulation of the biological behavior of ESCC.

Human tissues contain two isoforms of ER, ER $\alpha$ and $E R \beta$, which are generated by genes located on human chromosome 6q25 (11) and chromosome 14q22-24 (12), respectively. While several studies have identified the expression of ERs in ESCC (4,13-19), the distribution patterns of $\operatorname{ER} \alpha$ and $\operatorname{ER} \beta$ as well as their clinical implication remain highly controversial $(15,16,18,20)$. Accumulated data indicate a functional interaction between $\operatorname{ER} \alpha$ and $\operatorname{ER} \beta$ in human cells $(21,22)$. Comprehensive comparison of the available data on ER $\alpha$ and ER $\beta$ expression in ESCC is difficult since they are determined separately in different studies using different methods. We considered that simultaneous determination of both ER $\alpha$ and 
ER $\beta$ expression will allow us to analyze the quantitative relationship between $\mathrm{ER} \alpha$ and $\mathrm{ER} \beta$, which may have prognostic value for ESCC and aid in the better understanding of their involvement in the development of the malignant phenotype of ESCC.

The aim of this study was to determine the expression of ER protein and its correlation with clinical variables of ESCC patients.

\section{Materials and methods}

Ethics statement. The study was approved by the Ethics Committee of the Shantou University Medical College (Shantou, China), and only patients who provided written informed consent were included in the study.

Patients and tissues. Eighty-nine ESCC tissues were obtained from patients who underwent potentially curative esophagectomy from 2000 to 2006 at the Shantou Central Hospital (Shantou, China). These patients had received neither chemotherapy nor irradiation therapy prior to surgery. From these 89 cases, a total of 7 specimens of non-neoplastic epithelium were obtained for evaluating the expression of ER $\alpha$, and 9 specimens were obtained for ER $\beta$ evaluation. These specimens had undergone tissue microarray (TMA) construction before immunohistochemical staining. Relevant clinical data were retrieved from careful review of the medical records. All of the tumors were confirmed as ESCC by pathologists in the Clinical Pathology Department of the Shantou Central Hospital. The pathological stage of each cancer was determined according to the TNM system, and each lesion was graded histologically according to World Health Organization classification. The median follow-up time was 30.8 months (range, 1.4-54.4 months).

Immunohistochemistry. Mouse monoclonal antibodies for $\mathrm{ER} \alpha$ (F-10; dilution, 1:50) and $\operatorname{ER} \beta$ (14C8; dilution, 1:100) were purchased from Santa Cruz Biotechnology, Inc. and GeneTex Inc., respectively. Immunohistochemical staining was performed using the biotin streptavidin-peroxidase procedure as described previously (23).

Image analysis. Images were acquired using a Nikon microscope coupled to a Nikon DS-Fil digital camera (Nikon, Tokyo, Japan). Ten randomly selected discontinuous fields (x200) per slide were evaluated for each specimen. The positive area was stained yellow, and Image-Pro Plus software was used to quantify the integrated optical density (IOD). When evaluating the possible correlation between ER status and clinical outcome among individual patients, the cases were tentatively classified into two groups according to their ER IOD. A value of ER $\alpha$ IOD (range, 84-14,665) $\geq 5,200$ was considered as positive expression and a value $<5,200$ was considered as negative expression. A value of ER $\beta$ IOD (range, $3,877-31,923) \geq 18,000$ was considered as high expression and a value $<18,000$ was considered as low expression.

Statistical analysis. Results are expressed as means \pm SD. The statistical analyses between ER IOD and clinicopathological parameters of individual patients were carried out with the
Table I. Comparison of the clinicopathologic features between male and female esophageal squamous cell carcinoma patients.

\begin{tabular}{lccc}
\hline & \multicolumn{2}{c}{ Gender, n (\%) } & \\
\cline { 2 - 3 } Clinical parameters & Male & Female & P-value \\
\hline Age (years) ${ }^{\mathrm{a}}$ & $56.5 \pm 8.010$ & $63.8 \pm 7.229$ & 0.0005 \\
Tumor size (cm) & & & 0.129 \\
$\leq 3$ & $37(53)$ & $15(79)$ & \\
$>3$ - $\leq 5$ & $25(36)$ & $3(16)$ & \\
$>5$ & $8(11)$ & 1 & \\
Histologic grade & & & \\
G1 & $24(34)$ & $4(21)$ & \\
G2 & $40(57)$ & $12(63)$ & \\
G3 & $6(9)$ & $3(16)$ & \\
Invasive depth & & & 0.398 \\
T2 & $3(4)$ & $2(11)$ & \\
T3+T4 & $67(96)$ & $17(89)$ & \\
LN metastasis & & & \\
N0 & $37(53)$ & $9(47)$ & \\
N1+N2+N3 & $33(47)$ & $10(53)$ & \\
TNM classification & & & \\
IB+IIA+IIB & $38(54)$ & $9(47)$ & \\
IIIA+IIIB+IIIC+IV & $32(46)$ & $10(53)$ & \\
\hline
\end{tabular}

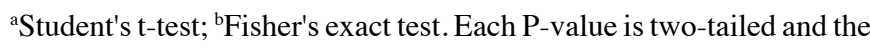
significant level was set at $\mathrm{P}=0.05$. Data are presented as means $\pm \mathrm{SD}$. LN, lymph node.

use of the Student's t-test, one-way ANOVA test, the MannWhitney U test, the Kruskal-Wallis test and paired t-test. Statistical analyses between gender and other clinicopathological characteristics were assessed with the Fisher's exact test. Correlation of ER $\alpha$ with ER $\beta$ was performed using Pearson's correlation. Overall survival (OS) curves of the patients were generated according to the Kaplan-Meier method, and statistical significance was calculated using the Breslow test. Statistical differences were examined using SPSS software. Each P-value is two-tailed, and the significance level was set at $\mathrm{P}=0.05$.

\section{Results}

Association between gender and clinicopathological parameters of the ESCC patients. The relationship between the gender of the patients and clinicopathological parameters are summarized in Table I. Females had a significantly older age at the onset of ESCC than that of males $(\mathrm{P}=0.0005)$. No significant association was detected between gender and tumor size, differentiation, depth of invasion, presence of lymph node metastasis or TNM classification of tumors.

Expression of ER protein in human esophageal non-neoplastic epithelium and carcinoma. Both $\mathrm{ER} \alpha$ and $\mathrm{ER} \beta$ were expressed 

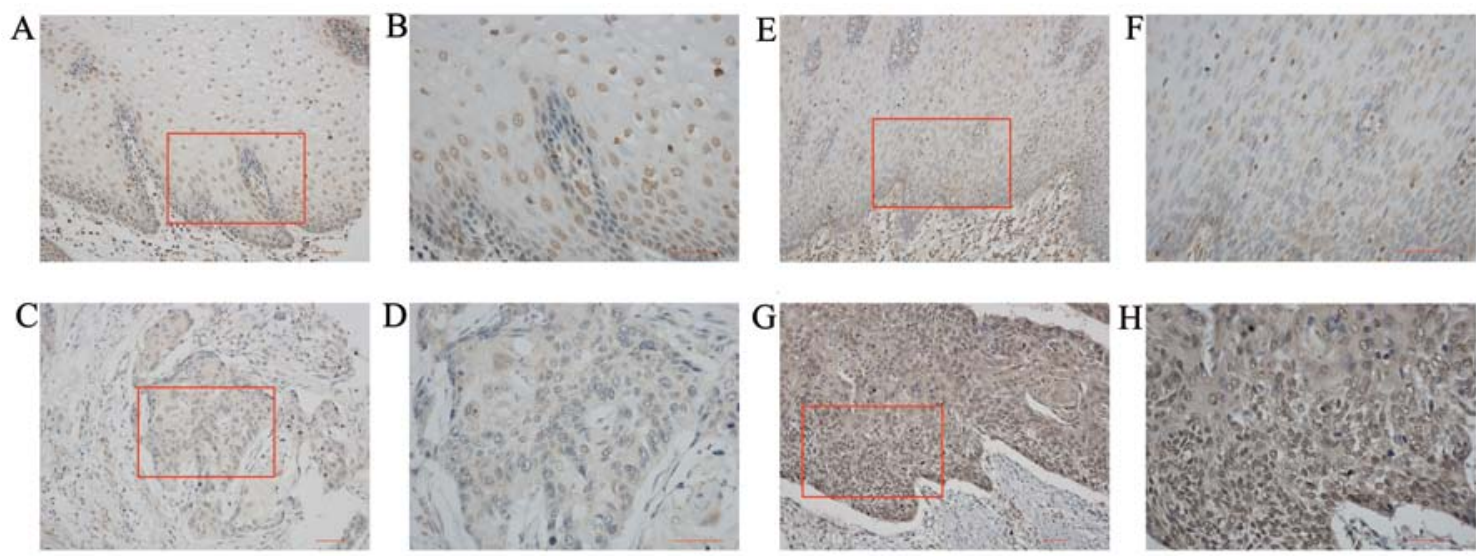

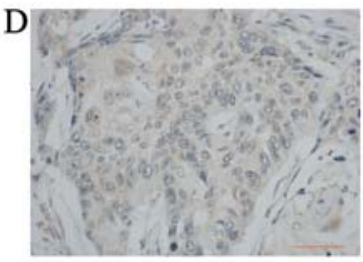

$\mathrm{ER} \alpha$
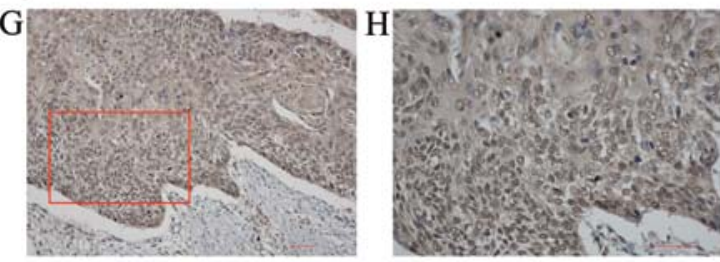

$\operatorname{ER} \beta$

Figure 1. Expression of ER $\alpha$ and ER $\beta$ in human non-neoplastic epithelium and ESCC. (A and B) Moderate ER $\alpha$ immunoreactivity was detected in the nuclei of non-neoplastic epithelial cells. (C and D) Weak ER $\alpha$ immunoreactivity was detected in the cytoplasm as well as in the nuclei of ESCC cells. (E and F) Negative to weak expression of ER $\beta$ was found in the nuclei of non-neoplastic epithelial cells. ( $\mathrm{G}$ and $\mathrm{H}$ ) Strong ER $\beta$ immunoreactivity was detected in both the nuclei and in the cytoplasm of ESCC cells. (B, D, F and H) Magnified areas of the corresponding embedded micrographs at the left. Scale bars, $50 \mu \mathrm{m}$.
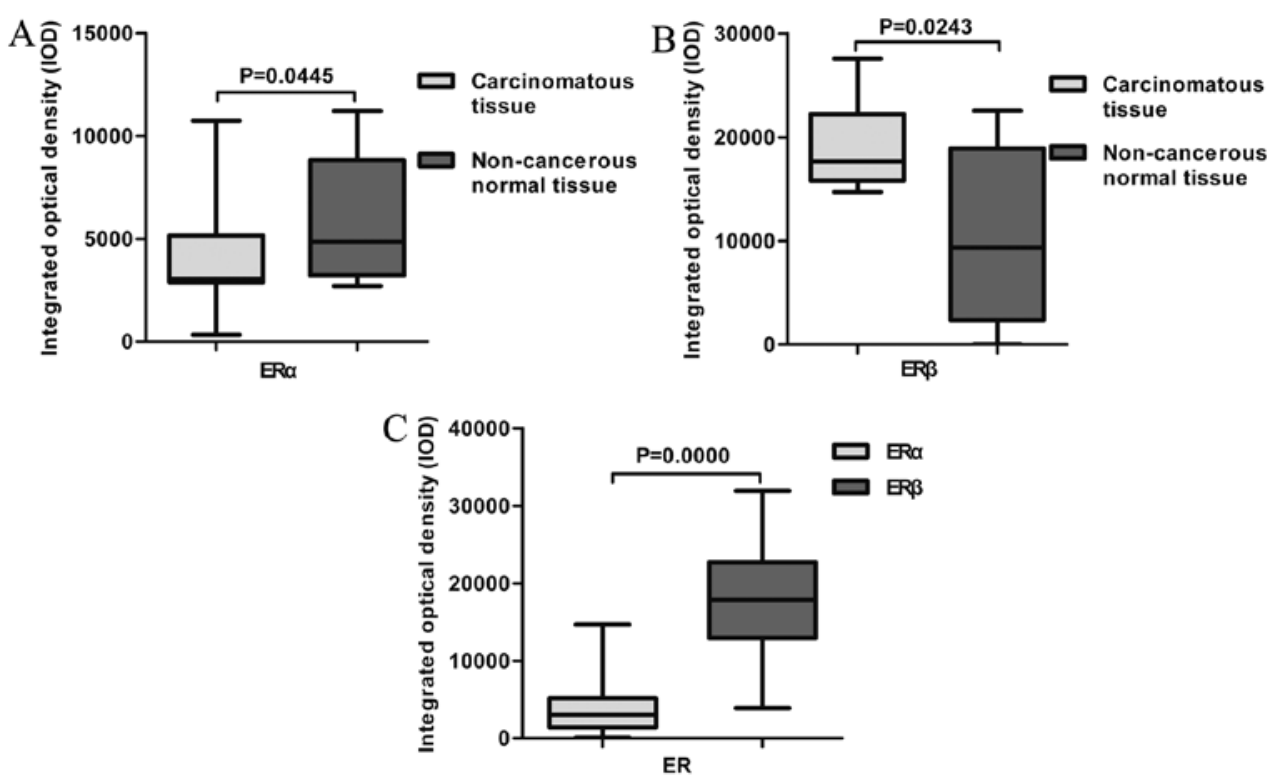

Figure 2. (A and B) Comparison of ER $\alpha$ and ER $\beta$ staining between the non-neoplastic epithelial and ESCC tissue samples. The expression of ER $\alpha$ was significantly weaker in ESCC than that in non-neoplastic epithelium $(\mathrm{P}=0.0445)$. However, the ER $\beta$ staining was significantly stronger in ESCC than that in the non-neoplastic epithelium ( $\mathrm{P}=0.0243)$. (C) Relationship between $\mathrm{ER} \alpha$ and ER $\beta$ expression in ESCC. There was a significantly inverse correlation between $\mathrm{ER} \alpha$ and $\mathrm{ER} \beta$ expression $(\mathrm{P}=0.0000)$.

in human esophageal non-neoplastic epithelium (Fig. 1A, B, $\mathrm{E}$ and F) with ratios of $3 / 7$ and $6 / 9$, respectively. ER $\alpha$ immunoreactivity was detected in the nuclei of carcinoma cells in 21/89 ESCC tissue samples. The mean value of ER $\alpha$ IOD in

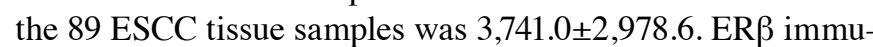
noreactivity was detected in the nuclei of carcinoma cells in 87/89 ESCC tissue samples. The mean value of ER $\beta$ IOD in 89 ESCC tissue samples was 17,998.7 $\pm 6,664.5$.

Based on the staining intensity, $\mathrm{ER} \alpha$ and $\mathrm{ER} \beta$ displayed opposite immunostaining patterns. For $\operatorname{ER} \alpha$, most of the cells showed moderate immunostaining in non-neoplastic epithelium (Fig. 1A and B), whereas negative to weak signals were observed in ESCC (Fig. 1C and D). However, ER $\beta$ immunoreactivity was detected to be much weaker in the non-neoplastic epithelium (Fig. 1E and F) than in ESCC (Fig. 1G and H). The expression difference between non-neoplastic epithelium and ESCC was statistically significant for both $\mathrm{ER} \alpha(\mathrm{P}=0.0445)$ and $\operatorname{ER} \beta(\mathrm{P}=0.0243$; Fig. $2 \mathrm{~A}$ and $\mathrm{B})$.

Association between the expression levels of the ERs and clinicopathological parameters of the ESCC patients. Associations between ER expression levels and clinicopathological parameters of the patients are summarized in Table II. There was a statistically significant inverse correlation between ER $\alpha$ IOD and invasive depth of the tumor $(\mathrm{P}=0.0426)$. No significant association was detected between $\mathrm{ER} \alpha$ status and age, gender, tumor size, differentiation, presence of lymph node metastasis or TNM classification of tumors. 
Table II. Association between ER $\alpha$ and ER $\beta$ and clinicopathological variables in 89 esophageal squamous cell carcinoma patients.

\begin{tabular}{|c|c|c|c|c|c|}
\hline \multirow[b]{3}{*}{ Clinical parameters } & \multirow[b]{3}{*}{$\mathrm{N}$} & \multicolumn{4}{|c|}{ IOD } \\
\hline & & \multicolumn{2}{|c|}{$\mathrm{ER} \alpha$} & \multicolumn{2}{|c|}{$\mathrm{ER} \beta$} \\
\hline & & Mean \pm SD & P-value ${ }^{a}$ & Mean \pm SD & $\mathrm{P}$-value ${ }^{\mathrm{b}}$ \\
\hline Age (years) & & & 0.5823 & & 0.7437 \\
\hline$\leq 58$ & 43 & $3,671.2 \pm 2,432.4$ & & $17,757.8 \pm 6,303.0$ & \\
\hline$>58$ & 46 & $3,806.3 \pm 3,437.9$ & & $18,223.9 \pm 7,047.7$ & \\
\hline Gender & & & 0.7264 & & 0.7158 \\
\hline Male & 70 & $3,557.7 \pm 2,702.0$ & & $17,863.6 \pm 6,842.6$ & \\
\hline Female & 19 & $3,831.9 \pm 3,004.4$ & & $18,496.5 \pm 6,109.7$ & \\
\hline Tumor size $(\mathrm{cm})$ & & & 0.3405 & & 0.9545 \\
\hline$\leq 3$ & 52 & $3,573.8 \pm 3,068.8$ & & $17,899.4 \pm 6,768.9$ & \\
\hline$>3-\leq 5$ & 28 & $3,388.4 \pm 2,183.5$ & & $18,299.6 \pm 6,599.9$ & \\
\hline$>5$ & 9 & $4,551.4 \pm 2,408.9$ & & $17,636.0 \pm 6,995.5$ & \\
\hline Differentiation & & & 0.4880 & & 0.7710 \\
\hline G1 & 28 & $3,249.8 \pm 2,501.5$ & & $18,034.6 \pm 6,696.4$ & \\
\hline G2 & 52 & $3,729.6 \pm 2,735.5$ & & $18,259.8 \pm 6,509.5$ & \\
\hline G3 & 9 & $4,480.7 \pm 3,646.0$ & & $16,495.1 \pm 8,010.6$ & \\
\hline Invasive depth & & & 0.0426 & & 0.2677 \\
\hline $\mathrm{T} 2$ & 5 & $5,373.8 \pm 1,291.0$ & & $14,773.2 \pm 7,422.8$ & \\
\hline $\mathrm{T} 3+\mathrm{T} 4$ & 84 & $3,511.1 \pm 2,787.2$ & & $18,190.7 \pm 6,616.0$ & \\
\hline LN metastasis & & & 0.9368 & & 0.2964 \\
\hline No & 46 & $3,593.9 \pm 2,508.5$ & & $17,281.6 \pm 6,602.0$ & \\
\hline $\mathrm{N} 1+\mathrm{N} 2+\mathrm{N} 3$ & 43 & $3,640.9 \pm 3,020.3$ & & $18,765.8 \pm 6,722.8$ & \\
\hline TNM classification & & & 0.6823 & & 0.1914 \\
\hline $\mathrm{I}+\mathrm{II}$ & 47 & $3,613.9 \pm 2,484.1$ & & $17,123.0 \pm 6,619.7$ & \\
\hline III+IV & 42 & $3,620.2 \pm 3,053.8$ & & $18,978.6 \pm 6,656.1$ & \\
\hline
\end{tabular}

a'Mann-Whitney U test and Kruskal-Wallis test were used; 'btudent's t-test and one-way ANOVA test were used. Each P-value is two-tailed and significant level was set at $\mathrm{P}=0.05$. Data are presented as means $\pm \mathrm{SD}$. ER, estrogen receptor; IOD, integrated optical density. LN, lymph node.
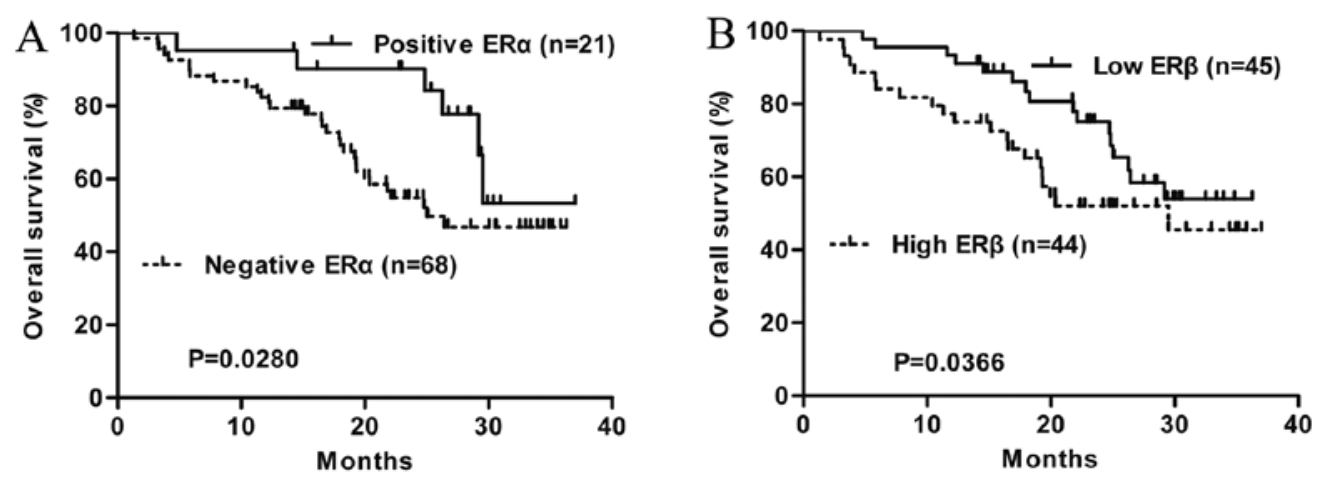

Figure 3. Overall survival (OS) of patients with ESCC stratified by the status of ER $\alpha$ and ER $\beta$ immunoreactivity. (A) The outcome of patients with ER $\alpha$ expression was significantly more favorable than that of patients without ER $\alpha$ expression $(\mathrm{P}=0.0280)$. (B) The patients with high ER $\beta$ immunoreactivity were significantly associated with worse survival than the patients with low $\mathrm{ER} \beta$ expression $(\mathrm{P}=0.0366)$.

No significant association was detected between ER $\beta$ status and age, gender, tumor size, differentiation, invasive depth, presence of lymph node metastasis or TNM classification of tumors.
ER $\alpha$ expression is inversely correlated with ER $\beta$ expression in ESCC. Paired t-test showed that the expression of ER $\beta$ was much stronger than that of $\mathrm{ER} \alpha(\mathrm{P}=0.0000$; Fig. 2C). There was also a statistically significant inverse correlation 
between the expression of ER $\alpha$ and ER $\beta$ in ESCC $(r=-0.2902$, $\mathrm{P}=0.0058$ ).

ER $\alpha$ and ER $\beta$ expression is of prognostic value for ESCC patients. Patients with ER $\alpha$ expression had a more favorable outcome than that of patients without ER $\alpha$ expression $(\mathrm{P}=0.0280$; Fig. 3A). However, high $\mathrm{ER} \beta$ levels were found to be associated with unfavorable outcome ( $\mathrm{P}=0.0366$; Fig. 3B).

\section{Discussion}

In the present study, a significantly lower level of ERa immunoreactivity was detected in ESCC tissues than that in the normal esophageal tissues, which was consistent with the finding of Zuguchi et al (18). ER signaling via the PI3K/AKT signaling pathway phosphorylates EZH2 at S21, reducing levels of H3K27me3 in uterine myometrial cells (24). Meanwhile, the expression frequency and expression levels of H3K27me3 were significantly higher in ESCCs than in normal tissues, and high expression of EZH2 was correlated with tumor aggressiveness and adverse patient outcome in ESCC $(25,26)$. Therefore, estrogen might exert a protective effect through ER $\alpha$ in esophageal squamous tissue. As for ER $\beta$, Wang et al (20) reported that ER $\beta$ expression was correlated with lower malignant potential of ESCC. Nevertheless, we found a high frequency of ER $\beta$ expression in carcinomatous tissues than that in non-cancerous normal tissues. This is consistent with the results of Kalayarasan et al (16) showing that ER $\beta$ was overexpressed in poorly differentiated SCC and adenocarcinoma when compared to normal esophageal mucosa. In lung adenocarcinoma, ER $\beta$-mediated estradiol was found to enhance epithelial mesenchymal transition through increased transcription of midkine (27). Thus, ER $\beta$ might also promote the process of ESCC by inducing epithelial mesenchymal transition. Meanwhile, several studies have demonstrated that the estrogenic action through ER signaling promotes the proliferation of carcinoma cells $(6,28)$. For example, treatment with ER $\beta$-specific agonist DPN led to a significant increase in the cell proliferation in primary urothelial cells, which predominantly expressed ER $\beta$ (8). From this point of view, our findings concerning the altered expression of $\mathrm{ER} \alpha$ and $\mathrm{ER} \beta$ may carry clinical implication for the treatment of ESCC. Reagents that upregulate the expression of ER $\alpha$ and/ or downregulate the expression of ER $\beta$ may be useful for the chemotherapy of ESCC patients.

In this study, carcinomatous and non-cancerous normal tissues of the esophagus were used, and all of the ESCC tissues were obtained from patients who underwent esophagectomy. The majority of cases were at a relatively high pathological stage (T3). Therefore, $\mathrm{T} 1$ cases were lacked, and only 5 cases were classified as T2. The dynamic changes in ER expression throughout the progression of ESCC could not be monitored. Future investigations should include normal esophageal tissues, low-grade dysplasia and high-grade dysplastic tissues, particularly $\mathrm{T} 1$ and $\mathrm{T} 2$ cases, to elucidate the potential function of ERs in the progression of ESCC.

We addressed the prognostic value of ER protein expression for patients with ESCC in the present study. A significant inverse correlation between the status of $\mathrm{ER} \alpha$ and the invasive depth of tumor was detected. The patients with ER $\alpha$-positive expression had a more favorable outcome than patients without ER $\alpha$ expression. As for ER $\beta$, Kaplan-Meier survival analysis showed that high expression of ER $\beta$ in ESCC was significantly associated with unfavorable clinical outcome of patients. These results indicate that negativity for $\mathrm{ER} \alpha$ and high expression of ER $\beta$ may be an unfavorable prognostic factor for ESCC patients. Since only immunohistochemistry was used in this study, further research using quantitative molecular methods are obviously required to clarify the prognostic value of ERs in ESCC.

McDonnell and Norris (21) reported that estrogenic signals through ER $\beta$ can inhibit ER $\alpha$-dependent transcription when both $\operatorname{ER} \alpha$ and $E R \beta$ are present in cells and are bound to estrogen. An inverse correlation between expression of ER $\alpha$ and that of ER $\beta$ was also demonstrated in lung cancer (22). In this study, we found that the expression of ER $\alpha$ was inversely correlated with that of ER $\beta$, which indicates that there may be some functional interactions between ER $\alpha$ and ER $\beta$ in ESCC. To the best of our knowledge, this represents a novel observation that has not been previously reported.

Prominent gender differences in the prevalence of ESCC should not be ignored. In the present study, the age of onset for female ESCCpatients was significantly older than that of male patients. Zuguchi et al (18) postulated that the gender differences in the prevalence of ESCC might be due to lifestyle differences between male and female patients. However, the difference in the onset age and the fact that all of the 19 female ESCC patients were older than the average postmenopausal age could not be explained by lifestyle differences. Rather, the estrogen levels as well as differential distribution of ER $\alpha$ and ER $\beta$ may contribute to the age- and menopause-related changes in risk for the female population.

In conclusion, our study revealed that ER $\alpha$ was downregulated and ER $\beta$ was upregulated, and the expression of ER $\alpha$ was negatively associated with that of ER $\beta$ in ESCC. The absence of ER $\alpha$ and high expression of ER $\beta$ indicate a poorer prognosis of ESCC. The use of selective ER modulators may be clinically effective for the treatment of ESCC patients. Future investigations are needed to delineate the mechanisms that contribute to the loss of ER $\alpha$ expression and the overexpression of ER $\beta$ during the progression of ESCC.

\section{Acknowledgements}

We thank Dr Sima Sarvari for assistance with the manuscript preparation.

\section{References}

1. Jemal A, Bray F, Center MM, Ferlay J, Ward E and Forman D: Global cancer statistics. CA Cancer J Clin 61: 69-90, 2011.

2. Sugimachi K, Matsuoka H, Matsufuji H, Maekawa S, Kai H and Okudaira Y: Survival rates of women with carcinoma of the esophagus exceed those of men. Surg Gynecol Obstet 164: 541-544, 1987.

3. Matsuoka H, Sugimachi K, Ueo H, Kuwano H, Nakano S and Nakayama M: Sex hormone response of a newly established squamous cell line derived from clinical esophageal carcinoma. Cancer Res 47: 4134-4140, 1987.

4. Ueo H, Matsuoka H, Sugimachi K, Kuwano H, Mori M and Akiyoshi T: Inhibitory effects of estrogen on the growth of a human esophageal carcinoma cell line. Cancer Res 50: 7212-7215, 1990. 
5. Derakhshan MH, Liptrot S, Paul J, Brown IL, Morrison D and McColl KE: Oesophageal and gastric intestinal-type adenocarcinomas show the same male predominance due to a 17 year delayed development in females. Gut 58: 16-23, 2009.

6. Niikawa H, Suzuki T, Miki Y, et al: Intratumoral estrogens and estrogen receptors in human non-small cell lung carcinoma. Clin Cancer Res 14: 4417-4426, 2008.

7. Mauro LV, Dalurzo M, Carlini MJ, et al: Estrogen receptor $\beta$ and epidermal growth factor receptor as early-stage prognostic biomarkers of non-small cell lung cancer. Oncol Rep 24: 1331-1338, 2010.

8. Teng J, Wang ZY, Jarrard DF and Bjorling DE: Roles of estrogen receptor alpha and beta in modulating urothelial cell proliferation. Endocr Relat Cancer 15: 351-364, 2008.

9. Rath-Wolfson L, Purim O, Ram E, Morgenstern S, Koren R and Brenner B: Expression of estrogen receptor $\beta 1$ in colorectal cancer: Correlation with clinicopathological variables. Oncol Rep 27: 2017-2022, 2012.

10. Hogan AM, Collins D, Baird AW and Winter DC: Estrogen and gastrointestinal malignancy. Mol Cell Endocrinol 307: 19-24, 2009.

11. Woo IS, Park MJ, Choi SW, et al: Loss of estrogen receptor-o expression is associated with hypermethylation near its ATG start codon in gastric cancer cell lines. Oncol Rep 11: 617-622, 2004.

12. Peng B, Lu B, Leygue E and Murphy LC: Putative functional characteristics of human estrogen receptor-beta isoforms. $\mathrm{J}$ Mol Endocrinol 30: 13-29, 2003.

13. Utsumi Y, Nakamura T, Nagasue N, Kubota $H$ and Morikawa S: Role of estrogen receptors in the growth of human esophageal carcinoma. Cancer 64: 88-93, 1989.

14. Utsumi Y, Nakamura T, Nagasue N, Kubota H, Harada T and Morikawa S: Effect of 17 beta-estradiol on the growth of an estrogen receptor-positive human esophageal carcinoma cell line. Cancer 67: 2284-2289, 1991.

15. Nozoe T, Oyama T, Takenoyama M, Hanagiri T, Sugio K and Yasumoto K: Significance of immunohistochemical expression of estrogen receptors alpha and beta in squamous cell carcinoma of the esophagus. Clin Cancer Res 13: 4046-4050, 2007.

16. Kalayarasan R, Ananthakrishnan N, Kate V and Basu D: Estrogen and progesterone receptors in esophageal carcinoma. Dis Esophagus 21: 298-303, 2008.
17. Wang QM, Yuan L, Qi YJ, Ma ZY and Wang LD: Estrogen analogues: promising target for prevention and treatment of esophageal squamous cell carcinoma in high risk areas. Med Sci Monit 16: HY19-HY22, 2010.

18. Zuguchi M, Miki Y, Onodera Y, et al: Estrogen receptor alpha and beta in esophageal squamous cell carcinoma. Cancer Sci 103: 1348-1355, 2012.

19. Yang H, Sukocheva OA, Hussey DJ and Watson DI: Estrogen, male dominance and esophageal adenocarcinoma: is there a link? World J Gastroenterol 18: 393-400, 2012.

20. Wang QM, Qi YJ, Jiang Q, Ma YF and Wang LD: Relevance of serum estradiol and estrogen receptor beta expression from a high-incidence area for esophageal squamous cell carcinoma in China. Med Oncol 28: 188-193, 2011.

21. McDonnell DP and Norris JD: Connections and regulation of the human estrogen receptor. Science 296: 1642-1644, 2002.

22. Kawai H, Ishii A, Washiya K, et al: Estrogen receptor alpha and beta are prognostic factors in non-small cell lung cancer. Clin Cancer Res 11: 5084-5089, 2005.

23. Liu S, Zhu N and Chen H: Expression patterns of human DAB2IP protein in fetal tissues. Biotech Histochem 87: 350-359, 2012

24. Bredfeldt TG, Greathouse KL, Safe SH, Hung MC, Bedford MT and Walker CL: Xenoestrogen-induced regulation of EZH2 and histone methylation via estrogen receptor signaling to PI3K/AKT. Mol Endocrinol 24: 993-1006, 2010.

25. He LR, Liu MZ, Li BK, et al: Prognostic impact of H3K27me3 expression on locoregional progression after chemoradiotherapy in esophageal squamous cell carcinoma. BMC Cancer 9: 461, 2009.

26. He LR, Liu MZ, Li BK, et al: High expression of EZH2 is associated with tumor aggressiveness and poor prognosis in patients with esophageal squamous cell carcinoma treated with definitive chemoradiotherapy. Int J Cancer 127: 138-147, 2010.

27. Zhao G, Nie Y, Lv M, et al: ERbeta-mediated estradiol enhances epithelial mesenchymal transition of lung adenocarcinoma through increasing transcription of midkine. Mol Endocrinol 26: 1304-1315, 2012.

28. Zhao G, Zhao S, Wang T, Zhang S, Lu K, Yu L and Hou Y: Estrogen receptor beta signaling regulates the progression of Chinese non-small cell lung cancer. J Steroid Biochem Mol Biol 124: 47-57, 2011. 